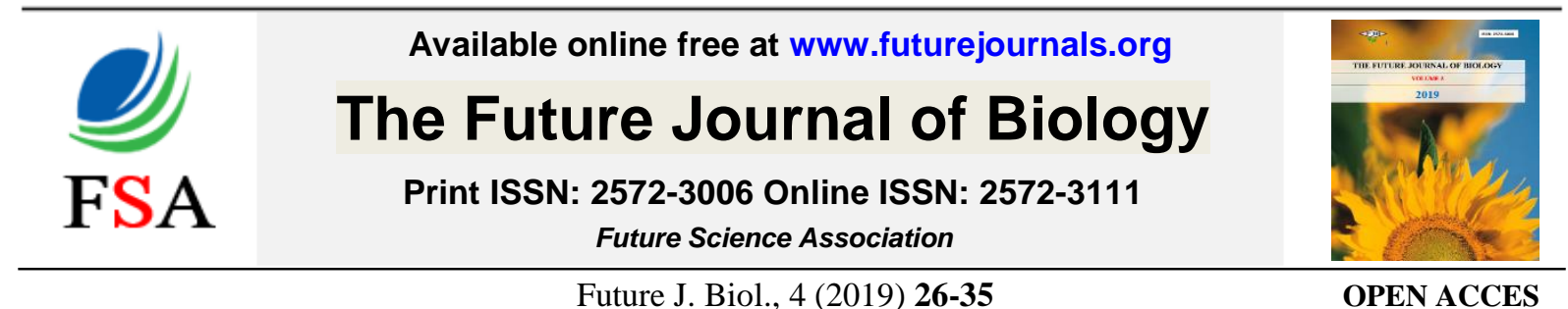

DOI: 10.37229/fsa.fjb.2019.11.07

\title{
IDENTIFICATION OF CHEMICAL COMPOSITION OF Eugenia aromatica AND ITS BIO-EFFICACY AGAINST Sitophilus oryzae (L.) AND Tribolium castaneum (HERBST)
}

\begin{abstract}
Abeer A. Salem
Plant Protection Res. Inst., Agric. Res. Cent., Dokki, Giza, Egypt.

*Corresponding author: medonoor200445@gmail.comＲeceived: 4 Oct. 2019 ; Accepted: 7 Nov. 2019

ABSTRACT: In this investigation plant oil and powder of E. aromatica were evaluated under laboratory conditions to determine their toxicity, fumigant effect and impact on F1 progeny of $S$. oryzae and T. castaneum adults. Essential oil and powder of flower buds obtained from Eugenia aromatica were purified and analyzed by Gas-Chromatography-Mass Spectrometer (GC-MC). The results obtained showed that the two products of $E$. aromatica had good disorders on the all tested parameters. For toxicity and fumigant effect the oil was the premier compared to powder. In addition, that the two products completely prevented the F1 emergence of the two insects. In respect of the toxicity and fumigation the T. castaneum was more tolerant than S. oryzae adults. Phytochemical analysis showed that euegnol (89.62\%) was the premier component of essential oil, while euegnol (78.66\%), caryophyllene $(6.30 \%)$, -a-Terpinyl acetate $(1.35 \%)$ were the major components for its powder. These findings suggest application of E. aromatica products as suitable tools as a potential source of insecticides, alternative to synthetic insecticides or using these products in integrated pest management program against stored product insects, especially $S$. oryzae or $T$. castaneum adults.
\end{abstract}

Key words: E. aromatica, oil and powder, insecticidal activity, phytochemical, stored product pests, T. castaneum and S. oryzae.

\section{INTRODUCTION}

Many disorders of human health and environment often due to heavy application of chemical synthetic insecticides against the insect attack both in field or storage. The toxicologists and entomologists offered a lot of solutions to those problems. Suggestion of evaluation the plant products (oil, extract and powder) as stored product protectants was the best of them. In respect of, earlier studies were carried out to investigate and identification the components of some plants responsible for the detrimental impacting on biology of some stored product insects. Among the various storage insect pests which damage the stored products, Sitophilus Spp. and Tribolium Spp. (Lal et al., 2017). One of the most important insects which cause $10-15 \%$ weight loss of the stored products is T. castaneum Duv. (Albushaba and Al Ameen, 2016). Insect damage may account for $10-40 \%$ of loss in stored grains, worldwide (Matthews, 1993) and 50\% of some countries (Fornal et al., 2007).
Therefore, biodegradable, nonresidual, equally effective and easily available botanicals may prove to be a better option to control insect pests including storage pests without affecting the quality of grains or seeds. (Lal et al., 2017). Botanical insecticides have broad spectrum activity, they are safe and relatively specific in their mode of action, easy to produce and use. Many studies have demonstrated contact and fumigant toxicity of plant essential oil and their components against several species of stored product insects at different life stages (Papachristos \& Stamopoulos, 2003; Pathipati, 2012 and Akinneye et al., 2019).

E. aromatica (clove) is an unopened flower bud belonging to Family Myrtaceae and has numerous medicinal properties, such as anti-oxidant, antiinflammatory, anti-microbial and antiseptic. The insecticidal activity of (clove) E. aromatica was demonstrated to insects of stored product by several authors, (Longe, 2011) evaluated fumigant effect of E. aromatica bud and Eucalyptus oil mixed 
formulations against Callosobrochus maculatus and recorded $100 \%$ mortality in all tested parameters. Essential oil of E. aromatica was effective as contact biorational against $S$. oryzae, $S$. zeamais, $T$. casaneum and Callosobrochus maculatus (Olotuah, 2014). Additionally, ethanolic extract essential oil of Eugenia aromatica was effective for the control of Ephestia caulella on coca beans since they completely inhibited development of the storage pest from eggs to adult stage at all concentrations, (Akinneye et al., 2019). Therefore, this study was undertaken to investigate contact and fumigant effect of Eugenia aromatica oil and powder against two of the most important of stored product pests $S$. oryzae and $T$. castaneum. Further phytochemical analysis was carried out by GC-MC to identify their major components.

\section{MATERIALS AND METHOD}

Laboratory experiments were carried out at the Department of Stored Product Pests Research, Plant Protection Research Institute, Sakha Agricultural Research Station Kafr-El-Sheikh, Egypt.

\section{Culturing of insects}

Adults of $S$. oryzae and $T$. castaneum were obtained from cultures that were regularly maintained in the laboratory and reared in laboratory-controlled chambers (incubator) at $27 \pm 2{ }^{\circ} \mathrm{C}$ and $70 \pm 5 \%$ relative humidity (R.H). The medium used for the insect culture were wheat grains for $S$. oryzae and crushed wheat for $T$. castaneum. Freshly emerged adults from the cultures were removed and then used for the bioassay in the next experiments.

\section{Eugenia aromatica plant}

Essential oil and flower buds of E. aromatica used in the current study were purchased from the local market. Clove (E. aromatica) flower buds were brought into the laboratory, washed thoroughly with water, after air dried then pulverized into fine powder using electric blinder. The fine powder was kept in airtight plastic container to avoid the absorption of moisture and then used in the next experiments.

\section{Bioassay methods}

\section{Contact toxicity (mixing with medium)}

Serious concentrations of E. aromatica oil were $(1,3,5,7$ and $10 \mathrm{ml} / \mathrm{kg}$ grain and 1, 3, 5, 7 and 10 of powder $/ 100 \mathrm{~g}$ grain were determined according to preliminary laboratory assessment. The different concentrations of E. aromatica oil and powder mentioned above were transferred on plastic containers $(11.5$ by $6 \mathrm{~cm}$ diameter $)$ containing samples of $20 \mathrm{~g}$ wheat grains, and then mixed with the grains to ensure uniform coating of the grain with the oil or powder. The jars which treated with oil were exposed to air for 30 minutes to allow the escape of the volatile solvent. Twenty adults of $S$. oryzae and $T$. castaneum (7-14 day old) were chosen randomly and transferred separately to treated samples in the plastic containers. On the other hand, the containers which contain untreated samples were served as control treatment. All treatments were replicated three times. Mortality counts were recorded after 1, 3, 5, 7 and 14 days, all results were corrected with formula by Abbott (1925).

The same experiment continued until the emergence to estimate the mean number of emerged adults, reduction of progeny. The LC50 and slope values were calculated by probity analysis (Finney, 1971).

\section{Fumigation toxicity}

a-oil

The fumigant effect of E. aromatica oil was determined according to the method described by Prates et al. (1998) with minor modification $E$. aromatica oil at rates of 3, 5, 10 and $15 \mathrm{ml} / \mathrm{L}$ were tested in $120 \mathrm{ml}$ glass jars each of them contains 10 adults of $S$. oryzae and T. castaneum (1-7) day old. Whatman No I filter paper were cut to $5 \mathrm{~cm}$ diameter, impregnated with tested concentrations and attached to the under surface of glass jars screw caps. Another groups of filter papers without oil were used for control. Three replicates were run for each concentration and control. The mortality was counted after 24, 48 and 72 hours.

\section{b- powder}

Similarly, E. aromatica powder as fumigant was evaluated According to Ofuya et al (2010) with minor modifications. $20 \mathrm{~g}$ of wheat grains were infested with ten unsexed adults (7-14 day old) $S$. oryzae and $T$. castaneum separately and then suspended in a piece of muslin cloth, over the powder in glass jars which contain serious of concentrations of $3,5,7,10$ and $15 \%$ g. The jars were covered with a lid properly screwed up to hold the muslin cloth and wheat grains in space and make the set up airtight. The jars without E. aromatica powders serve as control. All treatments plus control were replicated thrice. \% mortality was recorded after 1, 2 and 3 days post treatment, and the results were corrected with Abbott's formula.

\section{Phytochemical analysis}

\section{Instrument and method set-up}

A TSQ triple quadrupole GC-MS/MS instrument coupled with a Thermo ScientificTM TRACETM 1300 GC (Thermo Scientific, Austin, TX, USA) was used. Sample introduction was performed a Thermo ScientificTM AS3000 autosampler, and 
chromatographic separation using a Thermo ScientificTM TraceGold TG-5MS $30 \mathrm{~m} \times 0.25 \mathrm{MM}$ I.D. $\times 0.25 \mu \mathrm{m}$ film capillary column. Additional details of instrument parameters are displayed below. The column temperature was initially held at $55{ }^{\circ} \mathrm{C}$ and then increased by $5{ }^{\circ} \mathrm{C} / \min$ to $260{ }^{\circ} \mathrm{C}$ withhold 2 min then increased to 300 with $15^{\circ} \mathrm{C} / \mathrm{min}$. the injector temperature was kept at $250{ }^{\circ} \mathrm{C}$., helium was used as a carrier gas at a constant flow rate of $1 \mathrm{ml} / \mathrm{min}$., the solvent delay was $4 \mathrm{~min}$ and diluted samples of $1 \mu 1$ were injected automatically using Autosampler AS3000 coupled with GC in the split mode. El mass spectra were collected at $70 \mathrm{eV}$ ionization voltages over the range of $\mathrm{m} / \mathrm{z} 50-650$ in full scan mode. The ion source and transfer line were set at $200{ }^{\circ} \mathrm{C}$, and $280{ }^{\circ} \mathrm{C}$ respectively. The components were identified by comparison of them.

\section{Statistical analysis}

All data subjected statistical analyzed with analysis of variance (ANOVA) using Duncan Multiple Range Test (Duncan, 1955) at 0.05 level of probability for comparison between means of the different treatments.

\section{RESULTS}

Laboratory experiments were carried out to evaluate the plant oil and powder of E. aromatica against two global insect species of stored grain and their products $S$. oryzae and $T$. castaneum through mixing with medium method to determination of some criteria.

\section{E. aromatica oil}

\section{Effect on mortality}

Results obtained in (Table 1) clearly showed that the percent of mortality gradually increased as the concentration and exposure periods increased. For example, the rate of one $\mathrm{ml} / \mathrm{kg}$ grain achieved $16.7 \&$ $10.0 \%$ correct mortality and $100.0 \& 90.0 \%$ after one and 14 days for $S$. oryzae and $T$. castaneum, respectively. While, the rate of $7 \mathrm{ml} / \mathrm{kg}$ produced 86.7 $\& 63.3$ and $100 \& 93.3 \%$ mortality at one and 3 days post treatment for both insect tested. In addition, whenever the rate increased the exposure periods needed to investigate $100 \%$ mortality decreased. In general $S$. oryzae adults were more susceptible than the $T$. castaneum at the most of periods and concentrations. For pest management, in this study we can use the lower rates to protect the disinfested grain. But with the high infestation the present study suggests use the highest concentration $(10 \mathrm{ml} / \mathrm{kg})$ to curative the infested grains. In the case of middle infestation, the concentration of $5 \mathrm{ml} / \mathrm{g}$ grain in suitable to produce moderately control to the tested insect species.

Table 1. Mortality percentage of S. oryzae and T. castaneum adults affected by E. aromatica oil at indicated periods

\begin{tabular}{|c|c|c|c|c|c|c|c|c|c|c|c|c|}
\hline \multirow{3}{*}{$\begin{array}{c}\text { Concen. } \\
(\mathrm{ml} / \mathrm{kg})\end{array}$} & \multicolumn{12}{|c|}{ Exposure period (in-days) } \\
\hline & \multicolumn{2}{|c|}{1} & \multicolumn{2}{|c|}{3} & \multicolumn{2}{|c|}{5} & \multicolumn{2}{|c|}{7} & \multicolumn{2}{|c|}{14} & \multicolumn{2}{|c|}{$\begin{array}{l}\% \text { reduction of } \\
\text { progeny (F1) }\end{array}$} \\
\hline & S. $o$ & T. $c$ & S. $o$ & T. $c$ & S. $o$ & T. $c$ & S. $o$ & T. $c$ & S. $o$ & T. $c$ & S. $o$ & T. $c$ \\
\hline 1 & 16.7 & 10.0 & 56.7 & 30.3 & 60.0 & 53.3 & 86.7 & 80.0 & 100 & 90.0 & $100 \mathrm{~b}$ & $95.5 b$ \\
\hline 3 & 30.0 & 23.3 & 73.3 & 63.3 & 93.3 & 86.7 & 100 & 100 & - & - & $100 \mathrm{~b}$ & $100 \mathrm{~b}$ \\
\hline 5 & 50.0 & 46.7 & 93.3 & 83.3 & 100 & 100 & - & - & - & - & $100 \mathrm{~b}$ & $100 \mathrm{~b}$ \\
\hline 7 & 86.7 & 63.3 & 100 & 93.3 & - & - & - & - & - & - & $100 \mathrm{~b}$ & $100 \mathrm{~b}$ \\
\hline $\begin{array}{c}10 \\
\text { control }\end{array}$ & 100 & 100 & - & - & - & - & - & - & - & - & $\begin{array}{l}100 \mathrm{~b} \\
0.0 \mathrm{a}\end{array}$ & $\begin{array}{l}100 \mathrm{~b} \\
0.0 \mathrm{a}\end{array}$ \\
\hline
\end{tabular}

S.o: S. oryzae T.c: T. castaneum

\section{Toxicity effect}

Results shown in Table (2) obviously revealed that the degree of toxicity gradually increased with increasing of exposure period for both insects under test. For example, the LC50 values decreased from 4.4 to 0.97 and from 3.38 to $0.78 \mathrm{ml} / \mathrm{kg}$ grain at one and five days post treatment with $T$. castaneum and $S$. oryzae, respectively. Also, results presented that the response of $S$. oryzae to E. aromatica oil was higher than that of $T$. castaneum at the all periods of exposure. 
Table 2. LC50 values of $E$. aromatica oil against adults of $S$. oryzae and $T$. castaneum

\begin{tabular}{|c|c|c|c|c|c|c|c|c|}
\hline \multirow[b]{2}{*}{$\begin{array}{l}\text { Time in } \\
\text { (days) }\end{array}$} & \multicolumn{4}{|c|}{ T. castaneum } & \multicolumn{4}{|c|}{ S. oryzae } \\
\hline & LC50 & $\begin{array}{l}\text { Slope } \\
\text { Value }\end{array}$ & $\begin{array}{l}\text { Confide } \\
\text { Upper }\end{array}$ & $\begin{array}{l}\text { nce limits } \\
-\quad \text { lower }\end{array}$ & LC50 & $\begin{array}{l}\text { Slope } \\
\text { value }\end{array}$ & $\begin{array}{l}\text { Confiden } \\
\text { Upper }\end{array}$ & $\begin{array}{l}\text { nce limits } \\
-\quad \text { lower }\end{array}$ \\
\hline 1 & 4.40 & 2.69 & 5.5 & - $\quad 3.52$ & 3.38 & 2.84 & 4.22 & 2.70 \\
\hline 3 & 1.83 & 2.25 & 2.14 & $-\quad 1.51$ & 0.82 & 2.84 & 1.005 & -0.62 \\
\hline 5 & 0.97 & 2.71 & 1.16 & - $\quad 0.75$ & 0.78 & 1.32 & $1.21-$ & 0.78 \\
\hline 7 & - & - & & - & - & - & & - \\
\hline
\end{tabular}

\section{Effect on progeny}

Reduction of, progeny is one of the most criterion to evaluate the ability of a compound to deterrent the development of an insect. Results obtained in Table (1) markedly showed that the all concentrations tested of oil completely prevented the emergence of adults for the two tested insects. Hence the E. aromatica oil is considered suitable good alternative to synthetic insecticides to protect the stored grain and their products against the attack of stored product insects.

\section{E. aromatica powder}

Similarly, the powder of E. aromatica had the same trend of its oil both belong to the \% mortality or toxicity as well as the effect on the F1 spring. Results in Tables 1, 2, 3 and 4 clearly showed that the increase of concentration or exposure period had deterrent effect with the all tested aforementioned parameters.

Continually, $S$. oryzae adults were more susceptible than $T$. castaneum at the all tested concentrations along the experiment. The powder against both insects needed higher time or concentration to reach $100 \%$ mortality compared to oil.

Table 3. Mortality percentage of $E$. aromatica powder against $S$. oryzae and $T$. castaneum adults at indicated periods

\begin{tabular}{|c|c|c|c|c|c|c|c|c|c|c|c|c|}
\hline \multirow{3}{*}{$\begin{array}{l}\text { Concen. } \\
(\%)\end{array}$} & \multicolumn{12}{|c|}{ Exposure period (in-days) } \\
\hline & \multicolumn{2}{|c|}{1} & \multicolumn{2}{|c|}{3} & \multicolumn{2}{|c|}{5} & \multicolumn{2}{|c|}{7} & \multicolumn{2}{|c|}{14} & \multicolumn{2}{|c|}{$\begin{array}{l}\% \text { reduction of } \\
\text { progeny }(\mathrm{F} 1)\end{array}$} \\
\hline & S. $o$ & T. $c$ & S. $o$ & T. $c$ & S. $o$ & T. $c$ & S. $o$ & T. $c$ & S. $o$ & T. $c$ & S. $o$ & $T . c$ \\
\hline 1 & 13.3 & 6.7 & 40.0 & 26.7 & 53.3 & 56.7 & 76.7 & 63.3 & 83.3 & 80.0 & $100 \mathrm{~b}$ & $92.0 \mathrm{~b}$ \\
\hline 3 & 20.0 & 13.3 & 63.3 & 60.0 & 80.0 & 70.0 & 86.7 & 73.3 & 93.3 & 80.0 & $100 \mathrm{~b}$ & $100 \mathrm{~b}$ \\
\hline 5 & 26.7 & 20.0 & 86.7 & 76.7 & 93.3 & 83.3 & 100 & 90.0 & 100 & 100 & $100 \mathrm{~b}$ & $100 \mathrm{~b}$ \\
\hline 7 & 56.7 & 43.3 & 93.3 & 86.7 & 100 & 96.7 & - & 100 & - & - & $100 \mathrm{~b}$ & $100 \mathrm{~b}$ \\
\hline 10 & 76.7 & 53.3 & 100 & 93.3 & - & 100 & - & - & - & - & $100 \mathrm{~b}$ & $100 \mathrm{~b}$ \\
\hline 15 & 100 & 93.3 & & 100 & - & - & - & - & - & - & - & - \\
\hline control & & & & & & & & & & & $0.0 \mathrm{a}$ & $0.0 \mathrm{a}$ \\
\hline
\end{tabular}

S.o: S. oryzae

T.c: T. castaneum

Table 4. LC50 values of E. aromatica powder against adults of $S$. oryzae and $T$. castaneum at indicated periods

\begin{tabular}{ccccccc}
\hline \multirow{2}{*}{$\begin{array}{c}\text { Time in } \\
\text { (days) }\end{array}$} & LC50 & $\begin{array}{l}\text { Slope } \\
\text { value }\end{array}$ & $\begin{array}{c}\text { Confidence limits } \\
\text { Upper - lower }\end{array}$ & LC50 & $\begin{array}{c}\text { Slope } \\
\text { value }\end{array}$ & $\begin{array}{c}\text { Confidence limits } \\
\text { Upper }- \text { lower }\end{array}$ \\
\cline { 2 - 7 } & 8.26 & 2.24 & $10.32-6.61$ & 5.40 & 2.39 & $6.75-4.32$ \\
3 & 2.10 & 2.07 & $2.46-1.74$ & 1.52 & 2.15 & $2.07-0.67$ \\
5 & 0.95 & 1.59 & $1.19-0.76$ & 0.97 & 2.07 & $1.22-0.70$ \\
7 & 0.72 & 1.55 & $0.90-0.58$ & 0.36 & 1.53 & $0.45-0.29$ \\
14 & 0.14 & 1.03 & $0.42-0.002$ & - & - & - \\
\hline
\end{tabular}


For example, the rate of $7 \mathrm{ml} / \mathrm{kg}$ oils achieved $100 \%$ mortality for $S$. oryzae and T. castaneum after 3 days post treatment, while $\%$ powder of $E$. aromatica powder produced the same results for each insect at 7 days exposure period, respectively Table 1 $\& 3$. With regard to that the concentration of $1 \%$ powder (10000 PPM) nearly equal 10 times more than the concentration of oil, $1 \mathrm{ml} / \mathrm{kg}$ (1000 PPM). In addition, the effect of powder on $\mathrm{F} 1$ progeny had the same trend of oil in preventing the emergency of adults. Therefore, the oil was the strongest and the faster against the two tested insects.

\section{Fumigant effect on mortality}

a-oil

Results in (Table 5) showed that no one of the concentration used achieved $100 \%$ mortality through the three days of exposure except $S$. oryzae with 10 and $15 \mathrm{ml} / \mathrm{l}$ after three and two days, respectively. Also, results revealed that $T$. castaneum adults were more tolerant than $S$. oryzae. The percent of mortality of both insects increased with the increasing of concentration and the exposure period.

Table 5. Fumigant toxicity of $E$. aromatica oil and powder on adults of S. oryzae and T. castaneum

\begin{tabular}{|c|c|c|c|c|c|c|}
\hline \multirow{4}{*}{$\begin{array}{l}\text { Concentration } \\
(\mathrm{ml} / \mathrm{l})\end{array}$} & \multicolumn{6}{|c|}{ Exposure period (in-days) } \\
\hline & \multicolumn{6}{|c|}{ Oil } \\
\hline & \multicolumn{2}{|r|}{1} & \multicolumn{2}{|r|}{2} & \multicolumn{2}{|c|}{3} \\
\hline & S. oryzae & T. castaneum & S. oryzae & T. castaneum & S. oryzae & T. castaneum \\
\hline 3.0 & 10.0 & 0.0 & 26.7 & 6.7 & 43.3 & 13.3 \\
\hline 5.0 & 20.0 & 10.0 & 63.3 & 36.7 & 80.0 & 43.3 \\
\hline 7.0 & 43.3 & 20.0 & 70.0 & 43.3 & 83.3 & 63.3 \\
\hline 10.0 & 76.7 & 30.0 & 93.3 & 50.0 & 100.0 & 80.0 \\
\hline \multirow[t]{2}{*}{15.0} & 93.3 & 53.3 & 100.0 & 76.7 & - & 86.7 \\
\hline & \multicolumn{6}{|c|}{ Powder } \\
\hline $\begin{array}{c}\text { Concentration } \% \\
(\mathrm{w} / \mathrm{w})\end{array}$ & S. oryzae & T. castaneum & S. oryzae & T. castaneum & S. oryzae & T. castaneum \\
\hline 3.0 & 6.7 & 0.0 & 23.3 & 0.0 & 36.7 & 6.7 \\
\hline 5.0 & 10.0 & 3.3 & 43.3 & 23.3 & 63.3 & 40.0 \\
\hline 7.0 & 20.0 & 10.0 & 60.0 & 30.0 & 76.7 & 60.0 \\
\hline 10.0 & 66.7 & 20.0 & 80.0 & 50.0 & 100.0 & 73.3 \\
\hline 15.0 & 93.3 & 56.7 & 100.0 & 73.3 & - & 86.7 \\
\hline
\end{tabular}

\section{b-powder}

Results of E. aromatica powder (Table 5) had the same trend of its oil where the mortality gradually increased with the increasing of concentration and period of exposure. $\%$ mortality of $T$. castaneum was weak with the rates of 3,5 and $7 \%$ compared to that of $S$. oryzae. In general, the influence of $E$. aromatica oil had the strongest effect on the two tested insects if compared with that of powder. For example, the rate of $7 \mathrm{ml} / 1$ of oil performed $\%$ mortality ranged from 20 $83.3 \%$ with the both insects. While the rate of $7 \%$ of powder resulted $\%$ mean mortality between $10-76.7 \%$ with take account that rate of $7 \%$ powder nearly equal 10 times of $7 \mathrm{ml} / \mathrm{l}$ of oil.

\section{Fumigant toxicity of oil and powder}

When highlighting on the obtained results in Table (6), it is shown that the effect of the both powder and oil had the same trend where the action of them increases with the increasing of exposure period. Continually the impact of oil was the stronger according the concentration units used (ml/land $\%$ w/w). In addition, the response of $S$. oryzae to both materials was continuously higher than $T$. castaneum. 
Table 6. LC50 values of fumigant toxicity of $E$. aromatica oil and powder against adults of $T$. castaneum and $S$. oryzae

\begin{tabular}{|c|c|c|c|c|c|c|}
\hline \multirow{3}{*}{$\begin{array}{l}\text { Time in } \\
\text { (days) }\end{array}$} & \multicolumn{3}{|c|}{ T. castaneum } & \multicolumn{3}{|c|}{ S. oryzae } \\
\hline & \multicolumn{6}{|c|}{ Oil } \\
\hline & $\begin{array}{c}\mathrm{LC} 50 \\
\mathrm{ml} / \mathrm{l}\end{array}$ & $\begin{array}{l}\text { Slope } \\
\text { Value }\end{array}$ & $\begin{array}{c}\text { C. L } \\
\text { U- Lower }\end{array}$ & $\begin{array}{c}\mathrm{LC} 50 \\
\mathrm{ml} / \mathrm{l}\end{array}$ & $\begin{array}{l}\text { Slope } \\
\text { value }\end{array}$ & $\begin{array}{c}\text { C. L } \\
\text { U- Lower }\end{array}$ \\
\hline 1 & 7.16 & 4.19 & $6.66-11.47$ & 14.2 & 3.01 & $12.46-16.92$ \\
\hline 2 & 4.42 & 3.86 & $4.00-8.52$ & 8.52 & 2.71 & $6.33-13.23$ \\
\hline \multirow[t]{2}{*}{3} & 3.31 & 3.82 & $2.65-4.14$ & 5.93 & 3.23 & $5.40-6.47$ \\
\hline & \multicolumn{6}{|c|}{ powder } \\
\hline 1 & 8.58 & 4.88 & $6.86-10.23$ & 14.61 & 4.02 & $13.15-16.87$ \\
\hline 2 & 5.40 & 3.50 & $4.93-5.86$ & 9.76 & 3.40 & $8.94-10.80$ \\
\hline 3 & 3.95 & 3.45 & $3.47-4.36$ & 6.56 & 3.50 & $6.03-7.12$ \\
\hline
\end{tabular}

\section{Phytochemical analysis}

Chemical analysis by GC-MS of E. aromatica was carried out and the results summarized in tables $(7,8)$ concluded that, E. aromatica contains nine and five components for essential oil and powder respectively. Essential oil mainly contains high Eugenol, (89.62\%), 14-a-h-pregna $(2.72 \%)$ and 17-pentatriacontene $(2.25 \%)$ as well as minor components were 14-a-hpregna (0.73) HAhnfett $(0.55 \%)$, tetrapentacontane,
1, 54 dibromo. On the other hand the principle components of E. aromatica powder were phenol (Eugenol 78.66\%), caryophyllene (6.30\%), phenol, 2methoxy - 4 -92- propenyl) -,acetate (11.62\%) and trans -13- octadecenoic acid, methyl ester (1.06). Therefore, our results of chemical analysis, indicated that phenolic compound (Eugenol) was the major component of E. aromatica over $(89.62 \%)$ in oil and $(78.66 \%)$ in powder.

Table 7. Major components of $\boldsymbol{E}$. aromatica essential oil

\begin{tabular}{ccccc}
\hline R.T & Area $\%$ & Name of compounds & Molecular formula & $\begin{array}{c}\text { Molecular } \\
\text { weight }\end{array}$ \\
\hline 15.02 & 89.62 & Eugenol & C10 H12 O2 & 164 \\
18.14 & 0,63 & Docosane & C22 H46 & 380 \\
24.03 & 2.72 & 14 - a - H - Pregna & C21 H36 & 288 \\
24.17 & 2.60 & Tetrapenta contane, 1,54- dibromo & C54 H108 BR2 & 914 \\
26.51 & 2.25 & $17-$ Pentatriacontene & C35 H70 & 490 \\
26.92 & 0.73 & 14 - a - H - Pregna & C21 H36 & 288 \\
27.89 & 0.55 & HAhnfett & N/A & 0.0 \\
27.59 & 0.47 & HAHNFETT & N/A & 0.0 \\
27.89 & 0.55 & Tetrapenta contane, 1,54- dibromo & C54 H108 Br2 & 914 \\
\hline
\end{tabular}

Table 8. Names of chemical components present in $E$. aromatica powder

\begin{tabular}{|c|c|c|c|c|}
\hline R.T & Area $\%$ & Name of compounds & Molecular formula & $\begin{array}{c}\text { Molecular } \\
\text { weight }\end{array}$ \\
\hline 13.03 & 1.35 & - a - Terpinyl acetate & $\mathrm{C} 12 \mathrm{H} 20 \mathrm{O} 2$ & 196 \\
\hline 13.56 & 6.30 & Caryophyllen & C15 H24 & 204 \\
\hline 14.38 & 1.00 & Humulene & $\mathrm{C} 15 \mathrm{H} 24$ & 204 \\
\hline 14.82 & 78.66 & Eugenol & $\mathrm{C} 10 \mathrm{H} 12 \mathrm{O} 2$ & 164 \\
\hline 18.16 & 11.62 & $\begin{array}{l}\text { Phenol- 2- methoxy-4- (2- } \\
\text { propenyl)-acetate }\end{array}$ & $\mathrm{C} 12 \mathrm{H} 14 \mathrm{O} 3$ & 206 \\
\hline 24.14 & 1.06 & $\begin{array}{l}\text { Tran-13-Octadecenoic acid, } \\
\text { methyl ester. }\end{array}$ & $\mathrm{C} 19 \mathrm{H} 36 \mathrm{O} 2$ & 296 \\
\hline
\end{tabular}




\section{DISCUSSION}

Laboratory experiments were carried out to evaluate the insecticidal toxicity of oil and powder of $E$. aromatica plant against two global species of stored grain insect pests, $S$. oryzae and $T$. castaneum through studying toxicity, fumigant effect, offspring (F1 progeny). Results obviously showed that, oil and powder of $E$. aromatica have significant effect on all studied parameters with the two tested species. The contact toxicity of E. aromatica to adults of $S$. oryzae and $T$. castaneum depends on concentration, exposure period and insect species for example, the rate of $1 \mathrm{ml} / \mathrm{kg}$ grain gave $16.7 \& 10.0 \%$ mortality and $100 \&$ $90 \%$ after one and 14 days for $S$. oryzae and $T$. castaneum respectively, while the rate of $7 \mathrm{ml} / \mathrm{kg}$ grain produced $86.7 \& 63.3$ and $100 \& 93.3 \%$ mortality at one and 3 days post treatment for both tested insect, the effect of E. aromatica powder has the same trend. This report confirmed with Park et al. (2003) they concluded that, response of $C$. chinensis and $S$. oryzae exposed to direct contact of essential oil of Chamaecyparis obtuse varied according to insect species and application dose. Additionally, the contact toxicity of E. aromatica to adults of S. oryzae and $T$. castaneum depends on concentrations and exposure period, (Akinneye et al 2019). Results confirmed that, $S$. oryzae continually more susceptible than $T$. castaneum along the experiments as reported by Olotuah (2014). The differences in the response by the different insect pest species could be attributed to the morphological and behavioral characters of each specie (Tanpondju et al., 2002), and might be due to their feeding habit also (Olotuah, 2014). The results markedly showed that all studied concentrations completely prevented F1 progeny for two tested insects, therefore E. aromatica oil is considered good alternative to synthetic insecticides to protect stored grain against the attack of stored product pests. In this regard, the oil extract of $E$. aromatica is used to control stored product Coleopteran and Lepidoptera because of their high efficacy on all developmental stages of insect (Olotuah, 2014), the present results were also supported by the finding of Akinneye and Ogungbite (2016) in which some botanical oils were found to prevent the hatching of the eggs as well as adult emergence. The efficacy of this botanical oil could be as a result of inability of the insect to feed through the oil coat which may in return leads to starvation. On the other hand, botanical oils may also have disrupted the normal respiratory activity of the insects and this may lead to asphyxiation and sudden death (Akinneye and Ogungbite, 2016). Additionally, secondary metabolites which are present in plant oils could be responsible for the inability of the adult insect to emerge as reported by Mordue-Luntz and Nisbit (2000) and Yang et al. (2006) that secondary metabolites in botanicals are found to disrupt growth and reduce larvae survival as well as disrupt life cycle of insect species. Concerning to E. aromatica powder in the present study was also found to be completely preventing adult emergence at all concentrations used. These results agreed with Akinneye et al. (2019), who reported that powder of E. aromatica was found to be completely inhibit eggs hatching and emergence of adult of E. cautella with all concentration used, and this effect may be due to that the E. aromatica powder inhibit gaseous exchange Akinneye (2003). The action of the E. aromatica powder may be attributed to their storage odour in accordance with Lale and Abdulrahman (1990), that mortality of storage insects may be associated with the pungent odour produced by E. aromatica powder. Chemical analysis of E. aromatica was carried out to identify its principle components. The toxicity of essential oils tested against stored product was attributed to the chemical components of the oils (Koul et al., 2008 and Batish et al., 2008). The chemical composition of plant oils or powder was considered the subject of many studies by several authors (Zrira et al., 2003; Savan and Kucubay, 2013; Singh et al., 2008 and Akinneye et al., 2019). Some bioactive compounds such as the terpenoids, monoterpenes, and other compounds have been reported to be present in the (clove) E. aromatica essential oil (Bensky, 2004). In addition, Katunku et al. (2014) reported that saponin that is found in E. aromatica affect the respiratory system of insects.

In the present study, GC-MS analysis of $E$. aromatica essential oil mainly contain, Eugenol, (89.62\%), Ducosane (0.63\%), 14-a-h-pregna $(2.72 \%)$ 17-pentatria contend (2.25\%) HAhnfett (0.55\%), tetrapentacontane, 1, 54 dibromo. On the other hand, the principle components of E. aromatica powder were phenol (Eugenol 78.66\%), caryophyllene $(6.30 \%)$, a- Terpinyl acetate $(1.35 \%)$, Humulene (1.00\%), phenol, 2- methoxy - 4 -92- propenyl) ,acetate $(11.62 \%)$ and trans -13-octadecenoic acid, methyl ester (1.06). Therefore, our results of chemical analysis, indicated that phenolic compound (Eugenol) was the major component of E. aromatica over 89.62 and this findings are in agreement with Alma (2007) who concluded that the main components of essential oil of Turkey clove buds E. aromatica were Eugenol $87 \%$, Eugenol-acetate 8\%, B-caryophellene (3.56\%). Chemical constituents of essential oil of E. aromatica were determined by GC-MS, Eugenol, caryophellene, humolene, 2- methoxy- 3- (2- propenyl), 2- methoxy4- (2-propenyl0and 2- methoxy -5- (1-propenyl) represent a main component, Akinneye et al. (2019). In addition, the insecticidal potency of E. aromatica was suggested to be caused by Eugenol, caryophellene, humolene and other chemical compounds which have been proven to be insecticidal. This finding also agrees with the reports of Liu et al. (2010), Kim et al. (2003) that caryophellene and its derivatives are widely distributed among plant oils and reportedly possess acaricidal, insecticidal and repellent properties. Plant essential oils have potential as products for control of 
stored product pests because some of them are selective and have little or no harmful effects on -non - target organisms (Isman, 1999). E. aromatica is known to have sharp smell and mainly contain Eugenol over (87.62) and caryophellene (6.30\%) and the action of E. aromatica on these beetles could be as a result of stomach poisoning through feeding on whole or fragmented grain. In general, the complexity of the chemical composition of most of the volatile oils gives them low specificity (Bakkali et al., 2008), because biological activity is not assigned to a single mechanism of action, since the wide variety of chemical groups allows multiple targets in the cell (Burt, 2004).

The present study presented that oil or powder of E. aromatica had markedly fumigant effect on the tested insects. The potential use of essential oils as fumigants to control stored grain pests has been the subject of many studies (Shaaya et al., 1991 \& 1997; Bouda et al., 2001 and Lee et al., 2004). Its wellknown however that the toxicity of essential oils to stored product insects is influenced by the chemical composition of the oil which in turn depends on several factors and experimental conditions such as, climatic conditions harvesting time, method of extractions, nutritional status, plant part used and analytical conditions (Savan and Kucukbay, 2013). The insecticidal mode of action of the plant oils may be largely attributed to fumigant action; they may be toxic by penetrating the insect body via the respiratory system. The volatile oil of many plants have fumigant and gaseous action due to high volatilely, there for considered importance for control of stored product pests. Similar results reported by Kim et al. (2003) concluded that response of $S$. oryzae and $C$. chinensis to essential oil of cinnamon, garlic, and mustard oil using fumigation method, varied with insect species and time of exposure. Monoterpenoids are typically volatile and rather lipophilic compounds which can rapidly penetrate into insects and interfere with their physiological functions (Lee and Peterson, 2002). Regardless Ryan and Byrne (1988) suggested that the toxic effect of plants products may be attributed to a reversible competitive inhibition of acetylcholinesterase by occupation of the hydrophobic site of the enzyme active center. Additionally, Enan (2004) concluded that response of insects to essential oils and its constituents could be attributed to compound structure-activity relationship and physiological structure induced cellular changes resulting in poisoning of insects by blocking octopamin receptors.

\section{CONCLUSION}

The results obtained from this study suggest that both oil and powder of E. aromatica was effective for the controlling $\mathrm{S}$. oryzae and $T$. castaneum since they able to prevent adult emergence with all concentrations used. On the other hand, the effect of
E. aromatica depends on the time of exposure, concentrations, and insect species. Continually, $S$. oryzae was more sensitive followed by $T$. castaneum. Furthermore, phytochemical analysis of E. aromatica reveals the major components responsible for insecticidal action, such as, eugenol, caryophellene, humulen, -a-Terpinyl acetate. According to the finding mentioned above it can be safely concluded that E. aromatica either powder or oil are potential bio-pesticide and have no risk in handling, in contrast to synthetic chemical which have many complications. In addition, the effects of crude volatile oils are not particularly dangerous to consumer since they are commonly used in many pharmaceutical preparations (Bauer et al, 1990).

\section{REFERENCES}

Abbott, W. S. (1925). A method of computing the effectiveness of an insecticide. J. Econ. Entomol., 1 (8): 265-267.

Akinneye, J. O. (2003). Biology and control of the yam moth, Euzopheroides vapidella (Mann) Lepidotera: Pyralidae). Federal University of Technology, Akure, M. Tech. Thesis pp 65.

Akinneye, J. O. and Ogungbite, O. C. (2016). Entomotoxicant Potential of Some Medicinal Plant Against Ephestia cautella Infesting Cocoa Bean in Storage. Intern. J. Appl. Sci. Engine., 1: 59-68.

Akinneye, J. O.; Akinyemi, M. I.; Akinwotu, S. S. and Owoeye, J. A. (2019). Isolation and characterization of Eugenia aromatica oil against tropical warehouse Moth Ephestia cautella (Lepidoptera: Pyralidae) in cocoa beans. J. Pediatrics Neonatal Biology, 4 (1): 2573-9611.

Albushaba, S.H.S and Al-Ameen, F.A.M (2016). Efficacy of some plant powders against the flour beetle $T$. confusum (Coleoptera: Tennebrionidae). AL-Kufa University, J. biology, 8 (1).

Alma, H. K.; Ertas, M.; Nitz, S. and Kollmannsberger, H. (2007). Chemical composition and content of essential oil from the bud of cultivated Turkish clove (Syzigium aromaticum), BioResources, 2: 265-269.

Bakkali, F.; Averbeck, S.; Averbeck, D.; Idaomar, M. (2008). Biological effects of essential oils - a review. Food and Chemical Toxicology, 46: 446475.

Batish, R.; Singh, H. P.; Kohli, R. K. and Kaur, S. (2008). Eucalyptus essential oil as a natural pesticide," Forest Ecology and Management, 256 (12): 2166-2174.

Bauer, K. and Garbe, H. D. (1990). Surburg. Common fragrance and flavour materials (2nd ed.), VCH Verlagsgesellschaft Ltd., Weinheim, pp. 153-155. 
Bensky, D.; Clavey, S.; Stoger, E. and Gamble, A. (2004). Chinese Herbal Medicine. Materiamedica, 3 Edition. Pp. 20-25.

Bouda. H.; Tapondjou, L.A.; Fontem, D.A. and Gumedzoe, M. Y. D. (2001). Effect of essential oils from leaves of Ageratum conyzoides, Lantana Research, 37: 103-109.

Burt, S. (2004). Essential oils: their antibacterial properties and potential applications in foods - a review. Intern. J. Food Microbiology, 94: 223-253.

Duncan, B.D. (1995). Multiple range and multiple Ftest. Biometrics, 11: 1-42.

Enan, E. E. (2004). Molecular and pharmacological analysis of an octopamine receptor from American cockroach and fruit fly in response to plant essential oils. Archives of Insect Biochemistry and Physiology, 59: 161-171.

Finney, D.J. (1971). Probity analysis. 3rd edition. Cambridge University, London.

Fornal, J.; Jelinski, T.; Sadowska, J.; Grundas, S.; Nawrot, J.; Niewiada, A.; Warchalewski, J.R. and Blaszczak, W. (2007). Detection of granary weevil Sitophilus granarius (L.) eggs and internal stages in wheat grain using soft X-ray and image analysis. J. St. Prod. Res., 43: 142-148.

Isman, M. B. (1999). Pesticides based on plant essential oils. Pesticide Outlook, 10: 68-72.

Katunku, D.; Ogunwolu, E. O. and Ukwela, M. U. (2014). Contact toxicity of Canarium schweinfurthii Engl. Tissuesagainst Callosobruchus maculatus in stored Bambara groundnut. Intern. J. Agron. Agric. Res., 5: 20-28.

Kim, S.I.; Roh, J.Y.; Kim, D.H.; Lee, H.S. and Ahn, Y.J. (2003). Insecticidal a. activities of Aromatic plant extract and essential oils against Sitophilus oryzae and Callosobruchus chineensis. J. St. Prod. Res., 39 (3): 293 - 303.

Koul, O.; Walia, S. and Dhaliwal, G. S. (2008). Essential oils as green pesticides: potential and constraints," Pesticide International, 4 (1) 63-84.

Lal, M.; Ram, B. and Tiwari, P. (2017). Botanicals to cope stored grain insect pests: Areview. Int. J. Curr. Microbial. Appl. Sci., 6(6): 1583-1594.

Lale, N. E. and Abdulrahman, H. T. (1990). Evaluation of Neem (AzadirchtaIndica) A. Juss seed oil obtained by Different method and Callosobruchus aculates (Coleoptera: Bruchidae) in stored cowpea. J. St. Prod. Res., 35: 135-143.

Lee, S.; Byung, H. O.; Annins, P. C.; Turmaalii, F. and WonSik, C. H. O. I. (2004). Fumigant toxicity of essential oils from the Myrtaceae family and 1,8-cineole against 3 major stored-grain. J. St. Prod. Res., 40: 553-564.
Lee, S.C.J. and Peterson, J. R. (2002). Coats Fumigation toxicity of monoterpenoids to several stored product insects. J. St. Prod. Res., 39: 77-85.

Liu, Y. Q.; Xue, M.; Zhang, Q. C.; Zhou, F. Y. and Wei, J. Q. (2010). Toxicity of $\beta$-caryophyllene from Vitex negundo (Lamiales: Verbenaceae) to Aphis gossypii Glover (Homoptera: Aphididae) and its action mechanism. ActaEntomol Sin., 53: 396-404.

Longe, O.O. (2011). Infestigation into fumigant effect of commercially produced Eucalyptus oil and Eugenia aromatica dust against Callosobrochus maculates (Fabricius). International Conference on Biology, Environment and Chemestry, IPCBEE Vol 1 .

Matthews, G.A. (1993). Insecticide application in stores. Pages 305-315 in: Application technology for crop protection. G. A. Matthews and E. C. Hislop Eds.CAP International, Wallingford, UK,360 PP.

Mordue-Luntz, A. J. and Nisbet, A. J. (2000). Azadirachtin from the neem tree Azadirachta indica: its action against insects, Anais da SociedadeEntomológica do Brasil, 29: 615-632.

Ofuya, T.I.; Olotuah, O.F. and Akinyoade, D.O. (2010). The effect of storage on the efficacy of Eugenia aromatica in the control of Callosobrochus maculates (Fabricius) (Coleoptera: Bruchidae) pest. J. Appl. Sci. Environ. Manage., 14(1): 97-100.

Olotuah, O. F. (2014). Bio-efficacy of oil extract of Eugenia aromatica in the control of storage insect pests. Intern. J. Geology, Agric. Environ. Sci., 2: 410 .

Papachristos, P. and Stamopoulos, D. C. (2003). Selection of Acanthoscelides obtectus (Say) for resistance to lavender essential oil vapour. J. St. Prod. Res., 39 (4): 433-441.

Park, I.K.; Lee, S.G.; Choi, D.H.; Park, J.D. and Ahn, Y.J. (2003). Insecticidal activities of constituents identified in the essential oil from leaves of Chamaecyparis obtuse against Callosobruchus chinensis (L.) and Sitophilus oryzae (L.). J. St. Prod. Res., 39: 375-384.

Pathipati, U. R. (2012). Fumigant and contact toxic potential of essential oils from plant extracts against stored product pests," J. Biopesticides, 5 (2): 120128.

Prates, H. T; Santos, J. P.; Waquil, J. M.; Fabris J. D.; Oliveira, A. B. and Forster, J. E. (1998). Insecticidal activity of monoterpenes against Rhyzopertha dominica (F.) and T. castaneum (Herbst). J. St. Prod. Res., 34: 243-249.

Ryan, M.F. and Byrne, O. (1988). Plant-insect coevolution and inhibition of acetylcholinesterase. J. Chemical Ecology, 14: 1965-1975. 
Savan, E.K. and Kucukbay. F.Z. (2013). Essential oil composition of Elettaria cardamomum Maton. J. Appl. Biolo. Sci., 7(3): 42-45.

Shaaya, E.; Kostjukovski, M.; Eilberg, J. and Sukprakarn, C. (1997). Plant oils as fumigants and contact insecticides for the control of storedproduct insects. J. St. Prod. Res., 33: 7-15.

Shaaya, E.; Ravid, V.; Paster, N.; Juven, B.; Zisman, V. and Pissarev, V. (1991). Fumigant toxicity of essential oils against four major storedproducts insects. J. Chemical Ecology, 17: 499504.

Singh, G.; Kapoor, I. P. S.; Singh, P.; Heluani, C. S.; Lampasona, M. P. and Catalan, C. A. N. (2008). Chemistry, antioxidant and antimicrobial inves,tigations on essential oil and oleoresins of Zingiber officinale. Food and Chemical Toxicology, 46: 3295-3302.

Tanpondjou, L.A.; Alder, C.; Bouda, H. and Fontem, D.A. (2002). Efficacy of power and essential oil from Chenopodium ambrosioides leaves as post-harvest grain protectants against six-stored product beetles. J. St. Prod. Res., 38: 395-402.

Yang, Z.; Zhao, B.; Zhu, L.; Fang, J. and Xia, L. (2006). Inhibitory effects of alkaloids from Sophora alopecuroids on feeding, development and reproduction of Clostera anastomosis. Higher Education Press and Springer-Verlag. pp. 20-23.

Zrira, S.; Elamrani, A. and Benjilali, B. (2003). Chemical composition of the essential oil of Pistacia lentiscus L. from Morocco-a seasonal variation, Flavour Fragr. J., 18: 475-480. 